\title{
CONHECIMENTO DE UNIVERSITÁRIOS DE MEDICINA E ENFERMAGEM SOBRE A DOAÇÃO DE ÓRGÃOS E TECIDOS PARA TRANSPLANTE
}

\author{
Academic knowledge of Medicine and Nursing students on organ donation for transplants
}

\author{
Genilde Gomes de Oliveira', Emília Cervino Nogueira² e Izabel Cristina de Oliveira Lima
}

\section{RESUMO}

Objetivos: Identificar o conhecimento dos acadêmicos de Medicina e Enfermagem da Universidade Federal de Sergipe acerca da doação de órgãos e tecidos para transplante: legislação e critérios de confirmação do diagnóstico de Morte Encefálica (ME), identificar se a religião interfere na percepção e se os acadêmicos falam sobre doação de órgãos com familiares ou amigos. Métodos: Estudo quantitativo, descritivo e transversal com 85 acadêmicos (22 de Enfermagem e 63 de Medicina ) da UFS que responderam a um questionário semi estruturado contendo 20 perguntas. Resultados: O grupo tinha idade entre 16 e 34 anos: 55,3\% do sexo feminino predominantemente da religião católica (71,7\%). A maioria $(75,3 \%)$ informou que a religião praticada não esclarece sobre doação de órgãos e transplante. $80 \%$ declararam ter conhecimento sobre a legislação de transplante; $87 \%$ acreditavam que a ME é igual à parada cardiorrespiratória; $52,9 \%$ afirmaram conhecer o protocolo para diagnóstico de ME, embora o mesmo percentual tenha respondido que não existe diferença no diagnóstico em adulto e em criança; $70,6 \%$ sabiam da necessidade de exame complementar e 65,9\% sabiam que são necessários pelo menos dois médicos para atestar a ME, mas 45,9\% acreditavam que o intervalo mínimo para reavaliação clínica da ME em adulto fosse de duas horas. Quanto ao conhecimento sobre doação de órgãos e transplante após ingressar na Academia, 5,9\% responderam ser igual, 75,3\% afirmaram ser maior e 18,8\% acreditaram ser menor. Embora para $40 \%$ deles a carteira de identidade serviria como documento para autorizar doação, 76,5\% afirmaram posteriormente que a única atitude necessária seria informar a família. Conclusão: Os acadêmicos de Medicina e Enfermagem da Universidade Federal de Sergipe têm pouco conhecimento sobre doação de órgãos e tecidos para transplante, sendo que a maioria desconhece a legislação pertinente, o que pode interferir no envolvimento daqueles discentes, quando profissionais, no processo de doação de órgãos e tecidos para transplantes.

Descritores: Doadores de Órgãos; Doadores de Tecidos, Transplante, Estudantes de Medicina; Estudantes de Enfermagem.

\footnotetext{
Instituições:

1 Unidade de Terapia Intensiva do Hospital Universitário de Sergipe, Aracaju/SE

2 Central de Notificação, Captação e Distribuição de Órgãos de Sergipe, Aracaju/SE

3 Faculdade Estácio de Sergipe, Aracaju/SE
}

\section{Correspondência:}

Genilde Gomes de Oliveira

Rua Engenheiro Antônio Gonçalves Soares, 400 - CEP 49045-250 - Aracaju/SE

Tel.: (79) 32178941

E-mail: d.genilde@ig.com.br

\section{INTRODUÇÃO}

Atualmente, a Sociedade convive com incessantes descobertas e aperfeiçoamentos nas diversas áreas do conhecimento, que provocam questionamentos e certo grau de ansiedade, devido à velocidade dos avanços técnico-científicos e recursos tecnológicos com suas possibilidades de aplicação no cotidiano de trabalho dos seres humanos, em especial dos profissionais da área da saúde. Dentro desse contexto, o transplante de órgãos e tecidos é apenas um dos exemplos dessa inovação recente no panorama histórico mundial, que requer discussões de cunho ético, psicológico, legal, espiritual, cultural e social, envolvendo a comunidade científica e diversos segmentos da sociedade, pois confronta a morte de um indivíduo e as expectativas de mudança de qualidade de vida de outro(s). Entre esses dois extremos, somente a decisão favorável da família e sua autorização formal podem tornar concreta a doação de órgãos e tecidos para transplante. ${ }^{1}$ Os transplantes de órgãos vêm assumindo importante papel no tratamento de doenças terminais até então sem possibilidade de terapêutica clínica ou cirúrgica e os resultados obtidos estão contribuindo para uma sobrevida mais digna dos pacientes que necessitam dessa intervenção. ${ }^{2}$ 
A doação de órgãos e o transplante são temas complexos, sobre os quais é sabido existir concepções equivocadas por grande parcela da população. Tais concepções poderiam influenciar as crenças relativas à doação de órgãos, o que, possivelmente, explica o inexpressivo número de doações no Brasil.,3

A primeira lei brasileira a regular os transplantes de órgãos foi a 4.280/1963, que foi revogada pela de número 5.479/1968. Essa lei estabelecia o critério do consentimento informado, no qual a decisão sobre a doação pertencia aos familiares do potencial doador. ${ }^{4}$

Em 1997, a Lei 9.434, regulamentada pelo Decreto ${ }^{\circ} 2.268$, aprimorou e atualizou a legislação dos transplantes. Foi criado o Sistema Nacional de Transplantes (SNT), que é integrado pela Central Nacional de Notificação, Captação e Distribuição de Órgãos (CNNCDO) e pelas Centrais Estaduais, além dos estabelecimentos autorizados para captação e transplante. $\mathrm{O}$ SNT é o órgão central que gerencia e credencia os demais, bem como normatiza a distribuição dos órgãos em fila única. Essa lei ainda estabeleceu os critérios clínicos e exames necessários para o diagnóstico de morte encefálica (ME) com base na Resolução $\mathrm{n}^{\mathrm{o}} 1.480 / 1997$ do Conselho Federal de Medicina (CFM), e tornou obrigatória a todos os Hospitais a notificação de seus pacientes em ME. Estabeleceu sanções penais e administrativas quando do seu descumprimento. ${ }^{5}$

A Lei 9.434/97 ainda regulamentou a doação entre pessoas vivas, desde que não apresente riscos graves para o doador. Essa doação pode ser feita por pais, irmãos, avós, tios, filhos e cônjuges; quando não parente, ou ainda primos, é necessário um estudo de compatibilidade imunológica mais detalhado. ${ }^{5}$

A partir de 1997, ocorreu no Brasil uma intensificação do debate a respeito da doação de órgãos, o que envolveu pessoas e instituições das mais variadas áreas, quer seja na saúde pública, na mídia, na legislação brasileira e nos diversos grupos sociais. Isso levou a uma reflexão sobre algumas das implicações da doação e transplante, tais como sua necessidade social, critérios relativos aos procedimentos de transplante de órgãos, a nova lei aprovada sobre o assunto, listas de espera e as dificuldades de se encontrar um doador, entre tantas outras questões. ${ }^{6}$

Posteriormente, a Lei ${ }^{\circ}$ 10.211/2001 alterou o Art. $4^{\circ}$. da Lei 9.434/97, estabelecendo que a doação ocorre somente quando os familiares concordam com a mesma e assinam um termo de autorização. ${ }^{4}$

O transplante e a doação de órgãos humanos são temas polêmicos que têm despertado interesse e discussões em várias comunidades. A falta de esclarecimento, o noticiário sensacionalista sobre trafico de órgãos, a ausência de programas permanentes voltados para conscientização da população e o incentivo à captação de órgãos contribuem para alimentar dúvidas e arraigar mitos e preconceitos. $^{2}$

As Centrais Estaduais de Transplante vivenciam dificuldades não somente relacionadas à falta de conhecimento da população, que não autoriza a doação com medo do cadáver ficar desfigurado ou do órgão estar abastecendo uma rede de tráfico ou até por desconhecer o processo de transferência de um órgão de um individuo para outro com êxito, mas também por dificuldades impostas pelos profissionais da área de saúde que, por desconhecimento, preconceitos ou descaso, muitas vezes dificultam a Busca Ativa ou a entrevista com o familiar do potencial doador, contribuindo para estatísticas medíocres em relação à doação de órgãos e tecidos para transplante.

Um estudo sobre o conhecimento dos professores de uma faculdade de Medicina do Estado de São Paulo mostrou que a maioria destes teve dificuldade em responder sobre o diagnóstico de $\mathrm{ME}$ e a manutenção de potenciais doadores post mortem. Dado semelhante foi observado em médicos intensivistas de vários hospitais da cidade de Curitiba. Essa situação pode provocar assistência deficiente aos doadores, produzir enxertos de baixa qualidade e comprometer os resultados dos transplantes.?

Diante dessa problemática, foi percebida a importância de identificar o nível de conhecimento sobre o processo de doação especificamente entre estudantes de Medicina e Enfermagem, objetivando assim desvelar o conhecimento sobre tal temática. Vale ressaltar que em congressos e reuniões científicas acerca do assunto já se considera a necessidade da inclusão de disciplina sobre doação de órgãos para transplantes nos cursos de saúde como forma de facilitar o processo.

Este estudo busca identificar o conhecimento dos acadêmicos de Medicina e Enfermagem da Universidade Federal de Sergipe (UFS) acerca da doação de órgãos e tecidos para transplante, no que diz respeito à legislação pertinente à Morte Encefálica $(\mathrm{ME})$ e aos critérios de confirmação do diagnóstico, bem como se a religião interfere na percepção dos acadêmicos e, por fim, identificar se os acadêmicos falam sobre doação de órgãos com familiares ou amigos.

\section{MÉTODOS}

Trata-se de um estudo transversal, realizado na UFS com acadêmicos de Medicina e Enfermagem que estavam cursando o último período. Os dados coletados foram tratados de forma estatística descritiva utilizando a planilha Microsoft Excel.

Os acadêmicos foram submetidos a um questionário semi-estruturado fechado, a fim de identificar dados relevantes para que fosse possível alcançar os objetivos da pesquisa. Foram incluídos na pesquisa todos os estudantes de Medicina e Enfermagem que estavam cursando o último período e concordaram em participar da pesquisa, assinando o Termo de Consentimento Livre e Esclarecido (TCLE).

Participaram da pesquisa 85 estudantes, sendo 22 de Enfermagem e 63 de Medicina, que responderam o questionário que constava de vinte e uma questões relativas à doação de órgãos para transplantes englobando: religião, legislação, diálogo prévio com familiares e amigos sobre doação de órgãos e conhecimento a cerca do protocolo de ME. A pesquisa foi aprovada pelo Comitê de Ética em Pesquisa da UFS em outubro de 2008.

\section{RESULTADOS}

Os resultados estão descritos nas Tabelas 1 e 2 e nas Figuras 1, 2 e 3.

\section{DISCUSSÃO}

Ao avaliar o perfil do grupo pesquisado (Tabela 1), observaram-se jovens com idades que variam entre 16 e 34 anos, na sua maioria do sexo feminino, e que necessitavam ser instruídos sobre a conduta em casos de doação de órgãos, pois a educação médica é fator decisivo para o refinamento técnico do transplante e a melhora no índice de captação de órgãos é imprescindível na promoção de 
debates sobre transplante, envolvendo profissionais da saúde e a sociedade em geral, a fim de melhorar a estratégia para aprimorar esse procedimento e elevar sua discussão ética. ${ }^{7}$

Buscando definir o conhecimento prévio do estudante sobre doação de órgãos (Figura 1), percebeu-se que a maioria havia conversado sobre doação de órgãos e tecidos para transplantes com familiares e amigos. Esse dado é interessante, pois demonstra conhecimento prévio sobre o assunto; confrontamos esse resultado com outro questionamento registrado na figura (item 3), se o conhecimento que possuem após ingressar na Academia é maior, menor ou igual ao que possuíam anteriormente; 75,2\% responderam ser maior, mais de $10 \%$ afirmaram ser menor e nos questionamos como poderia a Academia contribuir para diminuir o conhecimento.

Tabela 1: Perfil dos Estudantes de Medicina e Enfermagem.

\begin{tabular}{lccc}
\hline Características & Perfil & $\begin{array}{c}\text { Número } \\
\text { absoluto }\end{array}$ & Percentual \\
\hline \multirow{2}{*}{ Gênero } & Masculino & 38 & $44,7 \%$ \\
\multirow{3}{*}{ Idade } & Feminino & 47 & $55,3 \%$ \\
& 16 a 24 anos & 53 & $62,4 \%$ \\
& 25 a 34 anos & 32 & $37,6 \%$ \\
Religião & Católica & 61 & $71,7 \%$ \\
& Doutrina Espírita & 12 & $14,1 \%$ \\
& Evangélica & 05 & $5,9 \%$ \\
& Cultos Afro-brasileiros & 01 & $1,2 \%$ \\
& Outros & 04 & $4,7 \%$ \\
& Não respondeu & 01 & $1,2 \%$ \\
& Sem religião & 01 & $1,2 \%$ \\
\hline
\end{tabular}

Figura 1 - Conhecimento prévio do acadêmico sobre doação de órgãos.

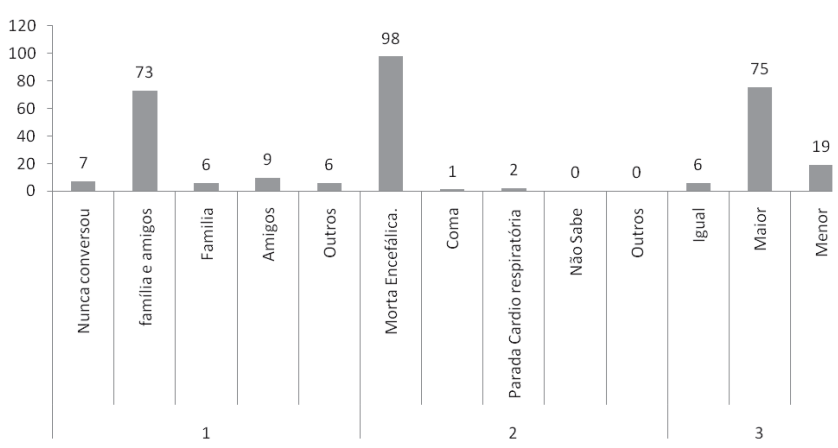

1- Em alguma situação, com a família ou amigos já participou de conversas sobre doação de órgãos e tecido para transplantes?

2- Para ser considerado doador de múltiplos órgãos o paciente deve possuir que condição clínica

3- O conhecimento que possuía sobre doação de órgão antes de ingressar na academia era:

A maioria dos alunos (98\%) respondeu que a confirmação de ME é o critério para efetivação da doação, porém alguns ainda consideram critérios a parada cardiorrespiratória e o coma.
Tabela 2: Conhecimentos gerais sobre Doação de Órgãos e Transplantes.

\begin{tabular}{|c|c|c|c|c|c|c|}
\hline \multirow{2}{*}{$\begin{array}{l}\text { Questões } \\
\text { A sua religião } \\
\text { procura esclarecer } \\
\text { sobre doação e } \\
\text { transplante de } \\
\text { órgãos? }\end{array}$} & \multicolumn{2}{|l|}{ Sim } & \multicolumn{2}{|c|}{ Não } & \multicolumn{2}{|c|}{$\begin{array}{c}\text { Não } \\
\text { respondeu }\end{array}$} \\
\hline & 20 & $23,5 \%$ & 64 & $75,3 \%$ & 01 & $1,2 \%$ \\
\hline $\begin{array}{l}\text { Tem algum } \\
\text { conhecimento sobre } \\
\text { a legislação de } \\
\text { transplantes? }\end{array}$ & 68 & $80 \%$ & 15 & $17,6 \%$ & 02 & $2,4 \%$ \\
\hline $\begin{array}{l}\text { Em sua opinião, } \\
\text { Morte Encefálica } \\
\text { (ME) é igual a } \\
\text { Parada Cardio- } \\
\text { respiratória? }\end{array}$ & 11 & $13 \%$ & 74 & $87 \%$ & 00 & 0 \\
\hline $\begin{array}{l}\text { Conhece o protocolo } \\
\text { para o diagnóstico } \\
\text { de ME? }\end{array}$ & 45 & $52,9 \%$ & 39 & $45,9 \%$ & 01 & $1,2 \%$ \\
\hline $\begin{array}{l}\text { Existe diferença } \\
\text { no diagnóstico de } \\
\text { ME em adulto e em } \\
\text { criança? }\end{array}$ & 38 & $44,7 \%$ & 45 & $52,9 \%$ & 02 & $2,4 \%$ \\
\hline $\begin{array}{l}\text { É necessário } \\
\text { Exame } \\
\text { Complementar para } \\
\text { diagnosticar a ME? }\end{array}$ & 60 & $70,6 \%$ & 25 & $29,4 \%$ & 00 & 0 \\
\hline $\begin{array}{l}\text { A Carteira de } \\
\text { Identidade serve } \\
\text { como documento } \\
\text { legal para } \\
\text { autorização da } \\
\text { doação? }\end{array}$ & 34 & $40 \%$ & 51 & $60 \%$ & 00 & 0 \\
\hline $\begin{array}{l}\text { Existem doações que } \\
\text { podem ser feitas em } \\
\text { vida? }\end{array}$ & 85 & $100 \%$ & 00 & 0 & 00 & 0 \\
\hline $\begin{array}{l}\text { Que órgãos ou tecidos } \\
\text { podem ser doados em } \\
\text { vida? } \\
\text { Rim } \\
\text { Medula Óssea } \\
\text { Fígado } \\
\text { Pulmão } \\
\text { Pele } \\
\text { Córnea }\end{array}$ & $\begin{array}{l}85 \\
78 \\
45 \\
09 \\
40 \\
02\end{array}$ & $\begin{array}{l}100 \% \\
91,8 \% \\
52,9 \% \\
10,6 \% \\
47,1 \% \\
2,4 \%\end{array}$ & $\begin{array}{l}00 \\
07 \\
40 \\
76 \\
45 \\
83\end{array}$ & $\begin{array}{l}0 \\
8,2 \% \\
47,1 \% \\
89,4 \% \\
52,9 \% \\
97,6 \%\end{array}$ & $\begin{array}{l}00 \\
00 \\
00 \\
00 \\
00 \\
00\end{array}$ & $\begin{array}{l}0 \\
0 \\
0 \\
0 \\
0 \\
0\end{array}$ \\
\hline
\end{tabular}

Ao registrar-se o conhecimento do aluno sobre a legislação do transplante (Tabela 2), apesar de $80 \%$ deles terem afirmado conhecer a legislação, ao serem questionados se conheciam o protocolo de ME, 45,9\% afirmaram não conhecer, enquanto 52,9\% informaram que sim.

Quanto à ME ser igual à parada cardiorrespiratória (Tabela 2), 11 alunos de final de curso ainda afirmaram que sim; embora a maioria (87\%) tenha afirmado que não. O dado é preocupante, tendo em vista ser preciso conhecimento e segurança para notificar ME, quadro esse que não tem similaridade com parada cardiorrespiratória. 
Embora se trate de estudantes, vale ressaltar que estão no último período da Academia.

A religião que aparece com maior freqüência é a católica (Tabela 1), seguida em ordem decrescente pela espírita, evangélica e por cultos afro-brasileiros. Especificamente no Brasil, o fator religião é importante. Por ser um país de dimensões continentais, com poucos centros transplantadores e grandes diferenças sociais, culturais e religiosas, as dificuldades relacionadas ao processo de doação tornam-se ainda maiores.

É essencial que haja integração entre os profissionais envolvidos, a fim de melhorar a qualidade da assistência ao potencial doador e à sua família, contribuindo dessa maneira, para incrementar a obtenção de órgãos adequados para transplante. A doação de órgãos poderia ser bastante facilitada se fosse priorizada e garantida a boa qualidade de comunicação entre os profissionais e a família do doador. ${ }^{8}$ Isso poderia ser iniciado nos templos, já que a doação é sinal de solidariedade, amor ao próximo e espírito altruísta. Entretanto, quando questionado aos estudantes se a religião praticada por eles costumava esclarecer sobre doação de órgãos e transplante (Tabela 2), 75,3\% responderam que não, mostrando a necessidade de debates e esclarecimentos.

Percebe-se ainda falta de conhecimento dos alunos ao se aprofundar nas perguntas sobre a ME. Quando questionados se existe diferença no diagnóstico da ME em adulto e em criança (Tabela 2), 44,7\% afirmaram que sim e 52,9\% responderam que não havia diferença. Quanto à necessidade de exame complementar para diagnosticar a ME (Tabela 2), 29,4\% afirmaram não ser necessário e 70,6\% informaram que sim. No diagnóstico da $\mathrm{ME}$, primeiro são feitos testes neurológicos clínicos, os quais são repetidos seis horas após. Depois dessa avaliação, é realizado um exame complementar (que pode ser um eletroencefalograma, arteriografia cerebral de quatro vasos ou outro). Isso implica que o diagnóstico de ME é definido através de exames clínicos e complementares, durante intervalos de tempo variáveis conforme a faixa etária de cada paciente, segundo a Resolução CFM 1.480/97. Percebe-se então que o aluno que está saindo da Academia poderá assumir suas funções em um Pronto Socorro ou uma Unidade de Terapia Intensiva (UTI) mesmo não conhecendo o protocolo de ME.

$\mathrm{O}$ entendimento da $\mathrm{ME}$ é um dos fatores que influem no processo de doação de órgãos. Geralmente, as famílias apenas ouvem falar desse conceito quando um ente querido evolui para esse diagnóstico em decorrência de uma lesão cerebral severa e súbita, o que dificulta a compreensão da idéia da cessação das funções do cérebro em um ser aparentemente vivo. $\mathrm{O}$ desconhecimento e/ou a não aceitação da ME é compreensível, uma vez que, classicamente, a morte era definida como a cessação irreversível das funções cardíaca e respiratória, o que gera resistência não somente na população, mas também entre profissionais da saúde. ${ }^{8}$

$\mathrm{Na}$ pesquisa foi questionado se existem doações que podem ser feitas em vida (Tabela 2). Todos os alunos responderam que sim, especificando que órgãos ou tecidos podem ser doados nessa situação. Chamou a atenção o fato de dois estudantes incluírem a córnea, comprovando total falta de conhecimento a respeito do tema.

Quanto aos critérios que contra-indicam a doação de órgãos (Figura 2 - item 5), a maioria dos entrevistados citou a presença de doença infecto-contagiosa, sepse, morte por causa desconhecida, demora na retirada dos órgãos, doença de origem viral e corpo não identificado, sendo que dois não tinham conhecimento. A classificação incorreta dos órgãos e tecidos que por essa razão são rejeitados diminui o número de transplantes. ${ }^{9}$ Essas observações sugerem carência de debates e exposições sobre transplante durante o curso e reforçam a necessidade de mais discussões sobre o assunto no currículo das faculdades de saúde do país. A desinformação sobre transplante pode provocar insegurança nas pessoas envolvidas na doação. ${ }^{7}$

Figura 2 - Conhecimento do acadêmico sobre os critérios para doação de órgãos.

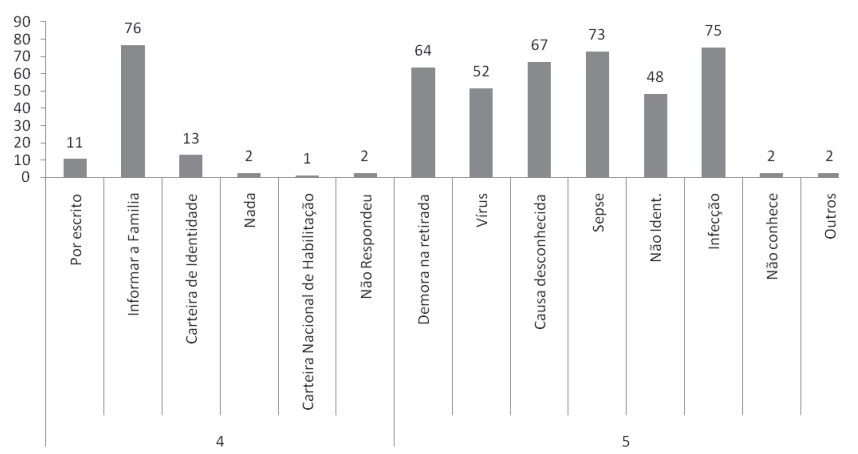

4 - De que forma deve ser autorizada a doação de órgãos?

5 - Que critérios contra indicam a doação de órgãos?

Observou-se falta de conhecimento dos estudantes que estão no último período da Academia, conforme foi demonstrado na pesquisa. Quando se questionou sobre quantos médicos seriam necessários para atestar a ME (Figura 3 - item 6), a maioria dos alunos respondeu dois médicos, 16 informaram três médicos e 11 disseram não saber. No item que questiona sobre as especialidades envolvidas no diagnóstico da ME (Figura 3 - item 7), houve um equilíbrio percentual entre os itens respondidos, caracterizando possivelmente a dúvida dos discentes, e ao se questionar qual o tempo mínimo para reavaliação da ME em adulto (Figura 3 - item 8), a maioria respondeu a cada duas horas, mas obtiveram-se ainda outras respostas, indicando necessidade de maior discussão na Faculdade sobre doação de órgãos e transplantes.

Figura 3 - Conhecimento do acadêmico sobre o protocolo de ME.

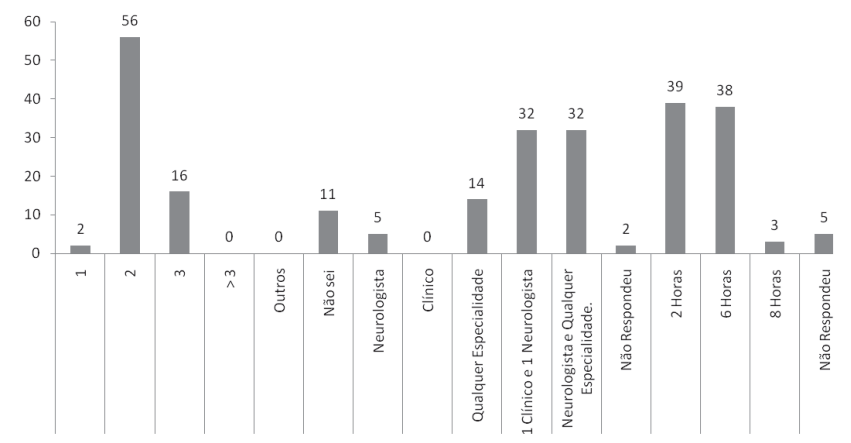

6- Quantos médicos são necessários para atestar a Morte encefálica?

7- Quais as especialidades médicas necessárias para atestar a morte encefálica?

8- Qual o tempo estipulado entre a realização do $1^{\circ}$ e do $2^{\circ}$ exame em adulto?

Quando questionados se a Carteira de Identidade serve como documento para autorização da doação (Tabela 2), 34 estudantes informaram que sim, um número considerado elevado, tendo em vista que há nove anos não se considera mais a Carteira de Identidade 
ou qualquer outro documento como fonte legal para autorização de doação; o critério adotado é autorização do cônjuge ou parente consanguíneo maior de idade, obedecida a linha sucessória, reta ou colateral até segundo grau inclusive, firmada em documento subscrito por duas testemunhas presentes à verificação da morte". ${ }^{4}$ À pergunta sobre qual a atitude necessária a quem deseja doar órgãos e tecidos (Figura 2 - item 4), apesar de 65 dos entrevistados terem revelado a necessidade de informar a família, verificou-se que 21 ainda acreditavam ser necessário deixar o desejo registrado de alguma forma e dois deles afirmaram não necessitar de atitude alguma, pois a doação é obrigação. Diante disso, observou-se que o tema doação e transplante de órgãos não tem sido discutido devidamente nos espaços sociais e nem mesmo nos currículos da área da saúde, havendo portanto muitas dúvidas e pensamentos equivocados a esse respeito..$^{10}$

Os dados levantam desafios importantes, como a desinformação da população em relação ao transplante e contra-indicação médica equivocada. A negativa de consentimento por parte da família poderia ser contornada mais facilmente se os profissionais envolvidos no processo de captação esclarecessem de forma competente as dúvidas dos familiares. Infelizmente, muitos profissionais não estão preparados para responder a questionamentos sobre doação. ${ }^{9}$ Embora o número de transplantes realizados no Brasil tenha aumentado nos últimos cinco anos, o índice de captação de órgãos (cerca de seis doadores por milhão de habitantes por ano) é insuficiente quando comparado ao de países mais avançados, que atingem números superiores a 22 doadores por milhão. O problema da captação, alocação e qualidade dos órgãos para transplante em nosso meio é fortemente vinculado à desinformação do meio médico e da população em geral. Muitos profissionais simplesmente ignoram a legislação vigente sobre transplantes e não notificam a ocorrência de ME aos órgãos competentes. ${ }^{7}$

A questão da escassez de órgãos para transplantes, mais acentuada no Brasil do que em outros países, somente será resolvida através de um intenso esforço de educação de toda a sociedade, incluindo, em curto prazo e em especial, os profissionais de saúde, atores que dão início e finalizam o processo. Não menos importante é a implementação de políticas de saúde pública que priorizem a prevenção de doenças que levam à indicação de transplante. ${ }^{11}$

\section{CONCLUSÃO}

Pode-se concluir com a pesquisa que acadêmicos de Medicina e Enfermagem da Universidade Federal de Sergipe têm pouco conhecimento sobre doação de órgãos e tecidos para transplante e que a maioria desconhece a legislação pertinente, fato este que comprova uma das dificuldades das centrais estaduais de transplantes na efetivação da doação, pois é de fundamental importância a parceria da equipe de saúde, já que se trabalha com uma população em sua maioria carente de informação, que lê pouco e é desatualizada.

É possível observar ainda a falta de conhecimento a respeito do protocolo de diagnóstico de ME, o qual é claramente explicado na Resolução CFM 1480/97, que delibera critérios para identificação de $\mathrm{ME}$ e formas de diagnóstico.

Evidenciou-se que a religião não interfere na percepção dos acadêmicos, já que os pesquisados informaram que ela não procura esclarecer sobre doação de órgãos e transplantes, ou seja, não há interferência positiva ou negativa, e quando se indaga sobre diálogos informais sobre transplantes e doações com amigos e familiares, observa-se que até existe o diálogo, mas de forma leiga, sem concepção ainda da responsabilidade de ser um agente da saúde, promotor da saúde.

Frente a essas conclusões, deve-se salientar a importância da implementação de disciplina de caráter obrigatório referente à doação de órgãos e tecidos para transplantes nas universidades e cursos da saúde, na tentativa de formar parceiros que participem efetivamente desse processo, ajudando conseqüentemente na redução de listas de espera e na melhoria das condições de vida de milhares de pessoas.

\section{AGRADECIMENTOS}

Gostaríamos de agradecer ao professor Doutor Antônio Carvalho da Paixão e à professora Mestra Cássia $\mathrm{M}^{\mathrm{a}}$ Macedo S. Faro, Coordenadores dos Departamentos de Medicina e Enfermagem, por terem permitido a realização da pesquisa; à professora Doutora Rosana Cipoloti, que viabilizou a aplicação do questionário junto aos acadêmicos de Medicina; a todos os estudantes de Medicina e Enfermagem que participaram voluntariamente da pesquisa e ao Coordenador da Central de Transplante de Sergipe, Benito Oliveira Fernandez, pelo apoio.

\section{ABSTRACT}

Purposes: To identify knowledge of students from the Academy of Medicine and Nursing of the Federal University of Sergipe related to the organ and tissue donation for transplants and the legislation and criteria to confirming the brain death (BD) diagnosis, to understand if religion interferes in the perception and to identify whether those students talk about organ donation t their family or friends. Methods: Quantitative, descriptive and cross study with 85 students from the UFS, 22 of Nursing and 63 of Medicine, who answered a semi structured questionnaire with 20 questions. Results: Group between 16 and 34 years old, 55.3\% female, predominantly Catholic (71.7\%). The majority (75.3\%) reported their religion is not clear about organ donation and transplantation. $80 \%$ was aware of the transplantation laws, $87 \%$ believe that tBD is equal to cardio-respiratory arrest, $52.9 \%$ claimed to know protocol for the diagnosis of BD, while the same percentage responded that there is no difference in the adult and children diagnosis, $70.6 \%$ know the need for additional examination and $65.9 \%$ know it is required at least two doctors to testify the BD, but $45.9 \%$ believed that the minimum clinical reassessment of $\mathrm{ME}$ in adult is two hours. As to the knowledge on organ donation and transplantation after joining the Academia, 5.9\% answered remain the same, $75.3 \%$ claimed to be higher and $18.8 \%$ believe it is lower. Although $40 \%$ said the ID Card is enough to authorize the donation, $76.5 \%$ said later that the only attitude required is to inform family. Conclusion: Nursing and medical students at the Federal University of Sergipe have little knowledge on organ and tissue donation for transplantation; the majority ignores the pertinent legislation, which may interfere in the involvement of students as professionals in the organ and tissue donation process for transplantation.

Keywords: Organ Donors; Tissue Donors; Transplantation; Students, Medical; Students, Nursing. 


\section{REFERÊNCIAS}

1. Alencar S.C.S de. Doação de órgãos e tecidos: a vivência dos familiares de crianças e adolescentes doadores. [Dissertação] Paraná: Universidade Federal do Paraná; 2006, $161 \mathrm{p}$.

2. Moraes M.W. Gallani MCBI, Meneghin P .Crenças que influenciam adolescentes na doação de órgãos. São Paulo. Rev. Esc Enferm USP. 2006;40(4)484-92.

3. Roza B.A. Efeitos do processo de doação de órgãos e tecidos em familiares: intencionalidade de uma nova doação. [Tese] São Paulo (SP). Universidade Federal de São Paulo-Escola Paulista de Medicina, 2005, 195 p.

4. Nogueira E.C. Captação de Órgãos em Sergipe e Fatores Associados a Efetivação de Potenciais Doadores [Dissertação]. Aracaju - Universidade Federal de Sergipe; 2008.

5. BRASIL. Lei 9434, de fevereiro de 1997. Dispões sobre a remoção de órgãos, tecidos e partes do corpo humano para fins de transplante e dá outras providências. Diário Oficial da União. Brasília, 5 de fevereiro de 1997. Seção 1, p. 2191-3.

6. Bendassoli PF. Percepção do corpo, medo da morte, religião e doação de órgãos.
Psicol. Reflex. Crit. 2001;14(1):225-40.

7. Galvão FHF,Caíres RA, Azevedo-Neto RS, Mory EK, Figueira ERR, Otsuzi TS et al. Conhecimento e Opinião de Estudantes de Medicina sobre Doação e Transplantes de Órgãos. Rev Assoc Med Bras. 2007;53(5):401-6.

8. Santos MJ, Massarollo MCKB. Processo de doação de órgãos: percepção de familiares de doadores cadáveres. Rev Latino-am Enfermagem. 2005;13(3):382-7.

9. Espíndola RF, Rodrigues BA, Penteado LT, Tan-ho G, Gozzan JOA, Freitas JAH. O Conhecimento de estudantes de medicina sobre o processo de doação de córneas. Arq Bras Oftalmologia. 2007;70(4) 581-4.

10. Silva AS, Matta AR, Matayoshi AG, Fujinami TI, Roza BA, Schirmer J. Estudo das Opiniões de Estudantes do ensino Médio sobre doação e transplantes de orgãos e Tecidos. In: Anais do XIII Congresso de Iniciação Científica da UNIFESP; 2005 São Paulo.

11. Ferreira ACM et al. O Processo de Doação - Transplante de Órgãos e Tecidos: O que Você Conhece Sobre o Tema?. Aliança Brasileira pela Doação de Órgãos e Tecidos. Disponível em www.adote.org.br. Acesso em 19 de fevereiro de 2009. 